\title{
Direct Shear Testing of a Marginal Material Using a Large Shear Box
}

\begin{abstract}
In Australia, Q181C Test Method of Direct Shear Testing to estimate the Effective Angle of Internal Friction at Constant Volume Conditions for Granular (Coarse Grained) Materials is commonly applied to assess the suitability of backfills for reinforced earth walls. This paper presents a comparison between the results of three series of shear box tests on a typical ripped rock material, of marginal quality, that might be considered as a possible backfill material for a reinforced earth wall. Tests performed used $300 \mathrm{~mm}$ and $60 \mathrm{~mm}$ shear boxes, soil samples prepared to sub-19 mm and sub-4.75 mm sizes, and a range of shearing rates. The effect of pre-testing samples was also considered. The results show that accurate effective friction parameter measurements for coarse grained, granular backfill soils require the use of fresh soil specimens for each shearing test; the use of a large shear box that can accommodate soils with relatively large particles; and careful selection of shearing rates so that shearing takes place under drained conditions. If the above requirements are compromised, the measured effective friction angle is likely to be a significant under-estimate of the true effective friction angle, increasing the likelihood of the material failing to meet prescribed material quality standards.
\end{abstract}

KEYWORDS: direct shear, large shear box, reinforced earth, size effect, shearing rate, marginal material

\section{Introduction}

Assessments of the stability of slopes, earth pressures on retaining walls, and the bearing capacity of foundations are often carried out using a Mohr-Coulomb strength model, based on the strength parameters $c$ and $\phi$. In free draining materials or situations where the rate of soil failure is likely to be slow, the effective strength parameters, $c^{\prime}$ and $\phi^{\prime}$ are used. These strength parameters are usually estimated from laboratory testing of representative samples.

Direct shear testing is a standard testing method employed for the estimation of soil shear strength parameters. An important advantage of this test is that it is possible to test larger soil samples with relative ease, and so soils with large particle sizes can be tested under conditions that more closely approximate those in the field.

Methods for carrying out direct shear tests for geotechnical engineering purposes are well established in practice. These methods have been formalized into testing standard documents such as ASTM D 3080-98 (1998) Standard Test Method for Direct Shear Test of Soils Under Consolidated Drained Conditions and AS 1289-6.2.2 (1998) Soil Strength and Consolidation TestsDetermination of the Shear Strength of a Soil-Direct Shear Test using a Shear Box.

In the past 20 years or so, there has been an increasing use of reinforced earth retaining structures (hereafter referred to as RE walls) in Australian and international construction practice, often associated with the construction of transportation infrastructure. The effective friction angle is a key design parameter used in the design of RE walls. In some cases, walls are designed prior to the letting of construction contracts, or the formulation of construction methodologies, and the exact nature of the backfill soils is unknown at the time of design. In order to accommodate this, walls are de-

\footnotetext{
Manuscript received May 16, 2007; accepted for publication February 18, 2008; published online March 2008.

${ }^{1}$ Dept. of Civil and Environmental Engineering. Yamaguchi University, Japan.

${ }^{2}$ Centre for Geotechnical and Materials Modelling. The University of Newcastle, Australia.
}

signed on the basis of an assumed effective friction angle, and this value is then prescribed as a minimum requirement in subsequent construction specifications.

The materials used in RE wall construction are often obtained from the sites where construction is taking place. As such, they are often poorly processed materials of "marginal" quality that only just comply with the design specifications. As these materials often contain particles of large size, the size of the test sample becomes an issue. Although the testing standards noted above have sufficient scope for application to large shear box tests, there are important technical issues regarding sample preparation difficulties for testing in large boxes and in the estimation of appropriate shearing rates. Because of these difficulties, the Queensland Department of Main Roads drafted a simplified standard for the routine testing of RE wall backfill soils using large shear boxes. The standard, Q181C, Effective Angle of Internal Friction at Constant Volume Conditions for Granular (Coarse Grained) Materials, was described in a draft form in 1994, and revised in 2002. In the 2002 publication, the standard provides for testing using shear box sizes of a minimum dimension of $300 \mathrm{~mm}$ by $300 \mathrm{~mm}$.

In applying the standard Q181C in routine practice, a number of technical questions arise. These include:

- First, does the method of Q181C ensure the selection of a suitable shearing rate to give accurate estimates of effective stress strength parameters? Many proposed marginal materials have high fines content, are weathered, or contain weak, crushable particles, and if the shearing rate for these materials is too fast, then fully drained conditions may not prevail and truly effective strength parameters may not be obtained.

- Second, as large test devices are relatively uncommon (compared with the availability of smaller devices), can adequate strength parameter estimates be obtained using a small shear box, where the sample has been modified to contain only the finer particle fraction, below an appropriately specified maximum size?

- Third, can the same sample be retested to reduce the effort associated with obtaining and handling large samples? That 
is, can reliable results be obtained if a single sample is sheared repeatedly under the three or four different normal stress values required to determine a shear strength envelope?

The aims of this experimental research were to critically examine each of the above issues, in the context of a material of inferior quality. While it is generally appreciated that coarser materials tested in larger devices will give higher effective friction values, the sensitivities to device size, particle size, shearing rate, and sample condition are seldom quantified. This paper provides data that help to appreciate the sensitivity of these issues.

\section{Background}

Direct shear testing, as was first used by Coulomb in 1776 (Lamb and Whitman 1969), has long been used to estimate the strength parameters for the analysis of slope stability, retaining wall, and bearing capacity problems. More recently, direct shear testing techniques have been extended to measure interface friction between soils and reinforcing elements in reinforced soil applications (Hausmann 1990; Lee and Manjunath 2000) and soils and foundation elements (Abderrahim and Tisot 1993).

Direct shear testing has many advantages over alternative test methods (Takada 1993; Terzaghi, Peck, and Mesri, 1996; Saada and Townsend 1981) including:

- the sample can be made to shear in a prescribed plane or zone;

- consolidation is one-dimensional ( $K_{o}$-consolidation);

- if appropriate sample dimensions are used, the shear deformation is approximately plane strain, and deformation occurs mostly by simple shear, which is often the design assumption of earth structures;

- if thin specimens are used, less time is required for consolidation and shearing due to a short drainage path, and drained tests can be performed relatively quickly;

- the test sample required can be relatively small or very large;

- the test operation is relatively easy.

Disadvantages of the direct shear test include changes in the area of the shear surface during shearing, and uncertainty in interpretation of the results due to non-uniformity of the stresses and strains that occur across the shear surface, and throughout the sample thickness.

Coarse granular soils are widely used as backfill material for embankments, trenches, and earth-retaining structures due to their high strength, good drainage, and compaction properties. Bauer and Zhao (1993) note that the testing of these coarse soils for shear strength can be a problem since most testing equipment is of small size, relative to the size of particles in the soil. A standard direct shear box (about 60 by $60 \mathrm{~mm}^{2}$ in plan view), is not suitable to test coarse granular materials. It is generally accepted that to obtain reasonable shear strength parameters for coarse granular soils, the size of the testing equipment should be many times the size of the largest particle. Q181C (2002) suggests that after consolidation, the sample thickness (including the gap) should not be less than seven times the diameter of the largest particles in the shear zone. This is, presumably, so that even if the shear zone extends into the sample within the box, it can develop without significant interaction with the rigid upper and lower plates that bound the sample. It is consistent with a shear band width of between 10 and 16 times the mean diameter, as suggested by Roscoe (1970) and Muhlhaus and Vard- oulakis (1987). Palmeira and Milligan (1989) report that for sufficiently fine samples, the scale of the test does not affect the measured values of friction angle, dilation angle, or maximum vertical stress to shear displacement ratio.

In general, in using the direct shear box to measure the drained strength parameters, the sample is first consolidated under the normal load, before shearing it at a rate that is sufficiently slow to ensure that significant excess pore water pressures are not created within the sample. Based on discussions in Jewell and Wroth (1987) and Bauer and Zhao (1993), it is generally accepted that for the shearing of granular backfills, a shearing rate of around $1 \mathrm{~mm} / \mathrm{min}$ is appropriate. Palmer (1999) recognizes the importance of shearing rate on the rate of pore pressure dissipation in all soils. He notes that even sands and silts can dilate during shear deformation, leading to the generation of significant suctions if the shearing rate is too fast, and resulting in an increase in the effective stress and an increase in the resistance to shear.

In a discussion by Day (1995) of a paper by Dounias and Potts (1993), it is noted that inaccurate direct shear results are common in clayey soil because samples are not consolidated prior to testing, or they are sheared too quickly. Kovacs (1997) suggests that in order to obtain the effective stress parameters of any soil, it is necessary to use a slower rate of shearing to allow induced pore pressures to dissipate. It is proposed that the appropriate rate of shearing can be achieved by ensuring that the time to sample failure ${ }^{3}$ is long enough to allow fully drained conditions to prevail in the sample, and further, that the time to failure can be estimated by monitoring the consolidation of the sample prior to shearing, so that a conservative estimate of the time to failure is given by $50 t_{50}$ or $12 t_{90}$, where $t_{50}$ and $t_{90}$ are the times to achieve $50 \%$ and $90 \%$ consolidation, respectively ${ }^{4}$. However, Kovacs (1997) also suggests that for clean sands and soils with high permeability, it is not necessary to go through a consolidation analysis procedure to estimate an appropriate shearing rate.

Yamamuro and Lade (1993) suggest that even at shearing rates that would result in drained conditions prevailing in a granular soil, the rate of shearing may still affect the measured soil strength at higher pressures. They found that soil specimens were less compressive, and their apparent strengths were increased, when the rate of strain was increased. They suggest that higher strain rates do not allow as much time for particle crushing and rearrangement, so that the soil appears less compressible and more dilatant, thus exhibiting slightly higher strength. However, these small changes are relatively insignificant for most drained tests.

\section{Methodology}

Tests were conducted on the same soil at two or three different shearing rates and using direct shear boxes of two different sizes. The results obtained from the tests are described by considering the shear strength characteristics and the measured effective internal friction angle for each shearing rate and box.

For each box size, and for each shearing rate, four individual shearing tests were performed under imposed normal stresses ranging from about $100 \mathrm{kPa}$ to $400 \mathrm{kPa}$. Specific details of each shearing test are given below.

The main objectives of these tests were as follows:

${ }^{3}$ Failure is defined as the point in the test where the maximum shear stress is reached.

${ }^{4}$ The basis for these values is unclear, and has not been located by the authors in the literature. 


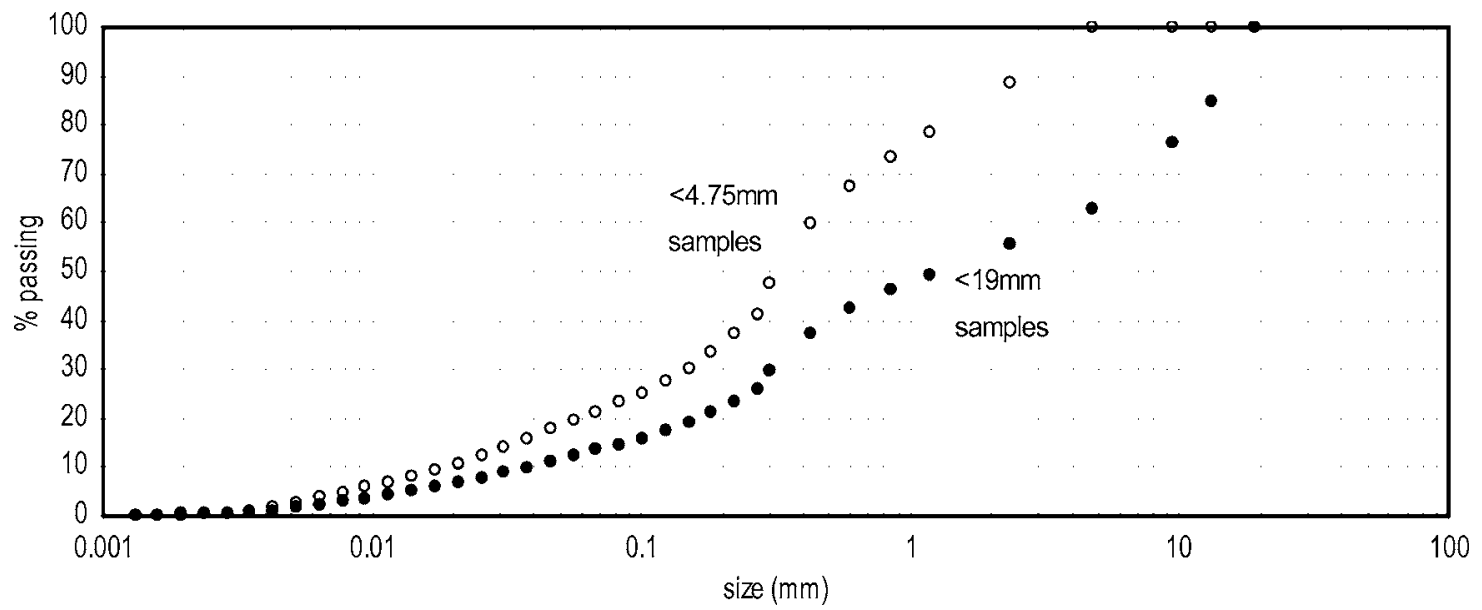

FIG. 1-Grain-size distribution curves for the two sample types tested.

- to study the factors that have an effect on the measured effective internal friction angle; that is, to examine the effects of factors such as applied normal stress and shearing rate;

- to examine what effect the scale of the test, has on the measured effective friction angle;

- to assess the validity of the testing method Q181C in terms of selecting a suitable shearing rate;

- to consider the effect of re-testing samples.

These were achieved in a series of studies described below.

\section{Apparatus, Materials, and Sample Preparation}

All direct shear testing for this study was carried out using multispeed direct shear equipment. The equipment was instrumented for automatic logging of both shear load and displacements. All instrumentation data were digitally displayed during the test, and outputs were interfaced with a personal computer. The large shear box tests were carried out using a Prolab machine with a shear box of $300 \mathrm{~mm}$ by $300 \mathrm{~mm}$ by $190 \mathrm{~mm}$ deep. The small shear box tests were carried out using a "Wykeham Farrence" direct shear machine, with a shear box of $60 \mathrm{~mm}$ by $60 \mathrm{~mm}$ by $50 \mathrm{~mm}$ deep.

Q181C (2002) gives guidance as to the maximum particle size of samples that may be tested in a shear box of a given size. For the large shear box with a depth of $190 \mathrm{~mm}$, a maximum particle size up to $19 \mathrm{~mm}$ was considered permissible, noting that after consolidation of the sample, the sample height is often reduced to around $130 \mathrm{~mm}$. The bulk sample, prepared to a maximum size of $19 \mathrm{~mm}$, could thus be tested directly. For the small shear box of $50 \mathrm{~mm}$ depth, a maximum particle size up to $5 \mathrm{~mm}$ was permissible.

The material employed in this testing program was a ripped siltstone rock, slightly weathered, taken from the excavated overburden of an open-cut coalmine in the Hunter Valley. This material was selected as, at one time, it was proposed to use it as RE wall backfill in an infrastructure development at the mine. In its delivered state, the sample was described as silty sandy GRAVEL, and it contained gravels up to cobble size. Before testing commenced, the bulk sample was screened to remove all particles greater than $19 \mathrm{~mm}$ (about $10 \%$ of the raw sample). These were crushed to pass the $19 \mathrm{~mm}$ sieve, and they were then returned to and blended evenly through the sample. Small box testing was carried out on a sample that had been modified by the removal of all material retained on the standard $4.75 \mathrm{~mm}$ sieve. The particle size distribution curves for each of the prepared samples are shown in Figs. 1(a) and 1(b). According to the Unified Soil Classification System (USCS), the prepared coarse samples are classified as (GM) silty sandy GRAVEL, fine to medium, pale gray siltstone gravels, fine to coarse sand, low liquid limit silt, and a trace of pale gray clay of low plasticity. After removal of the 4.75-19 $\mathrm{mm}$ fractions, the sample was modified to (SM) silty gravelly SAND.

The grain-size distribution curves of the soil were obtained using a sieve analysis of the coarse fractions and by using a Malvern laser diffraction particle sizing device for the sub-150 $\mu \mathrm{m}$ fraction. From Figs. $1(a)$ and $1(b)$, it is found that $D_{50}=1.2 \mathrm{~mm}, C_{\mathrm{U}}$ $=92.1$ for the large shear box sample, and $D_{50}=0.33 \mathrm{~mm}, C_{\mathrm{U}}$ $=44.3$ for the small shear box sample.

Table 1 summarizes the general characteristics of the soil. The dry density and optimum water content values were determined according to the AS 1289.5.1.1 (2003) Test Method. The Los Angeles value was determined on a "B" grading (9.5-13.3 mm and 13.2-19 mm fractions) using the AS 1141.23 (1999) Test Method. The Los Angeles value was determined on a "B" grading (9.5-13.3 $\mathrm{mm}$ and $13.2-19 \mathrm{~mm}$ fractions) using the AS 1141.23 (1999) test method. While not strictly a "soft" rock (LAV>40), an LAV of 36 is greater than that generally accepted in engineering applications such as pavement gravels and aggregates $(\mathrm{LAV}<30)$, confirming its status as a marginal material (Lay 1985).

TABLE 1-Physical properties of the tested sample.

\begin{tabular}{|c|c|c|c|c|c|c|}
\hline \multirow[b]{2}{*}{$\begin{array}{l}\text { Soil } \\
\text { size, } \\
\mathrm{mm}\end{array}$} & \multicolumn{3}{|c|}{ Atterberg limits ( $-4.75 \mu \mathrm{m}$ fraction) } & \multicolumn{2}{|c|}{ Standard compaction (whole soil) } & \multirow{2}{*}{$\begin{array}{c}9.5-19 \mathrm{~mm} \\
\text { Los Angeles } \\
\text { abrasion value, } \\
\% \text { dry mass }\end{array}$} \\
\hline & $\begin{array}{c}\text { Liquid } \\
\text { limit, } \\
\%\end{array}$ & $\begin{array}{c}\text { Plastic } \\
\text { limit, } \\
\%\end{array}$ & $\begin{array}{c}\text { Plasticity } \\
\text { index, } \\
\%\end{array}$ & $\begin{array}{l}\text { Maximum dry } \\
\text { density, } \mathrm{g} / \mathrm{m}^{3}\end{array}$ & $\begin{array}{c}\text { Optimum water } \\
\text { content, } \%\end{array}$ & \\
\hline$<4.75$ & 28.7 & 19.4 & 9.3 & 1.83 & 13.6 & 36 \\
\hline$<19.0$ & & & & 1.86 & 14.8 & \\
\hline
\end{tabular}


In general, soils exhibit maximum strength when compacted at a moisture content that is slightly wetter than optimum moisture content and this approach is usually adopted in earthworks construction. This means that conditions are usually unsaturated during construction of compacted earth structures. However, after construction, it may happen that moisture contents approach the saturated state because of rain, groundwater, poor drainage, etc. Therefore, the shear box tests were performed in accordance with Q181C, under conditions that simulated the worst likely conditions that might be encountered under field conditions; that is, under effectively saturated conditions.

\section{Components of This Study}

\section{Study 1: Assessment of the Effect of Shearing}

Rate-The effect of shearing rate on the measured effective angle of friction was assessed by conducting sets of tests at different shearing rates, different by factors of approximately 10 ; nominally $5,0.5$, and $0.05 \mathrm{~mm} / \mathrm{min}$. Actually, for the large box, tests were carried out at 7.06, 0.63 , and $0.05 \mathrm{~mm} / \mathrm{min}$, and for the small box, tests were carried out at 6.03 and $0.42 \mathrm{~mm} / \mathrm{min}$. The desired assessment of rate effects is made by comparing results at different speeds for the same box size.

\section{Study 2: Assessment of Effect of the Scale of the} Test - It is generally understood that for a given size of shear box, there is some maximum particle size that can be present in a sample without causing excessive localized disturbance to the stresses and strains with in the box during testing. The various direct shear testing methods each provide some guidance in this regard. Using the guidance and Q181C and AS 1289.6.2.2 (1998), the maximum particle sizes for the large box and the small box of $<19 \mathrm{~mm}$ and $<4.75 \mathrm{~mm}$ are found to meet the suggested requirement, respectively.

Hence, in considering why the results of small box and large box direct shear tests might be different, two factors must be examined:

I different sizes of the box, assuming that geometric effects could cause differences in the developed shear zones;

II different sizes of largest particles, assuming that mechanical interaction of large particles affects measured soil strength.

In order to explore each of these possible effects separately, three sets of shear box tests were conducted:

(i) testing with the large shear box using a sample with a $19 \mathrm{~mm}$ maximum particle size;

(ii) testing with the large shear box using a sample with a $4.75 \mathrm{~mm}$ maximum particle size;

(iii) testing with the small shear box using a sample with a $4.75 \mathrm{~mm}$ maximum particle size.

Therefore, by comparing the results of tests (ii) and (iii), we can assess the likely effects of factor I, and by comparing the results of tests (i) and (ii), we can assess the likely effects of factor II. The tests for (i) to (iii) were carried out for sufficiently similar shearing rates in the large direct shear box and the small direct shear box so that shearing rate effects can be reasonably disregarded. The rates employed were 0.63 and $0.42 \mathrm{~mm} / \mathrm{min}$, respectively.

\section{Study 3: Assessment of the Effect of Retesting} Samples - As noted earlier, large shear box testing requires large amounts (in excess of $50 \mathrm{~kg}$ ) of sample to be used. To make the large shear box testing more efficient in commercial practice, it has been suggested that the same sample can be retested under different normal stress values to obtain the required shear strength values. This aspect of the research involved performing a set of second shearing tests on samples that had already been used once in a direct shear test. The results were compared with results for samples that had not been previously tested (new samples). In between tests, previously used samples were dried, sieved, and crushed (to split any lumps). They were then tested again (retested).

A summary of all of the tests performed in this research is presented in Table 2.

\section{Results}

In considering the results that follow, note that the shear stresses reported were calculated simply by dividing the shear load by the initial (maximum) shear area of the sample, without applying an area correction (neither Q181C (2002) or ASTM D3080-98 (1998) prescribe the use of such a correction).

It is also important to appreciate the choice of horizontal strain as the unit for the horizontal axis of plots of individual shear test results. Q181C (2002) suggests that the shear strain should be approximated by the shear displacement divided by the height of the sample. This assumes that the thickness of the shear zone is equal to the full sample height. The problem with this definition is that for very thick samples, a significant thickness of superfluous sample may lie outside the shear zone (and hence, not contribute to the measured shear strength), but still affect the magnitude of the calculated shear strain. The true shear strain is generally unable to be determined in a direct shear test, since the height of the shear zone is difficult to determine (Lamb and Whitman 1969; Muhlhaus and Vardoulakis 1987; Palmeira and Milligan 1989; Finno et al. 1997; Han and Drescher 1993).

ASTM D3080-98 (1998) specifies that shear stress be simply plotted against shear displacement. While there are no issues with this for routine purposes, for this study, it makes the comparison of results from large and small shear boxes difficult. In the present study, an alternative to using either shear strain or shear displacement is adopted. It is referred to as the horizontal strain, taken to be the shear displacement divided by the initial length of the surface being sheared. This assumes that the thickness of the shear band is not only a function of the particle diameter in the test sample, but also of the length over which it develops within the shear box (Palmeira and Milligan, 1989). The validity of this idea is evident in the relative alignment of test results for small and large shear boxes achieved, as shown in the figures that follow.

\section{Results of Study 1: The Effect of Shearing Rate}

In order to give effective strength parameters, the shearing rate should be sufficiently slow to ensure completely drained conditions. The method used by Q181C (1994; 2002) to determine a shearing rate uses the data recorded during the consolidation phase as an indicator of the relative rate of pore pressure dissipation, and hence as a basis for shearing rate selection. The precise basis of the 
TABLE 2-Summary of tests performed and their purpose.

\begin{tabular}{|c|c|c|c|c|c|}
\hline & \multirow[b]{2}{*}{$\begin{array}{l}\text { Specimen } \\
\text { number }\end{array}$} & \multicolumn{2}{|c|}{ Normal stress, $\mathrm{kPa}$} & \multirow{2}{*}{$\begin{array}{l}\text { Shearing } \\
\text { rate, } \\
\mathrm{mm} / \mathrm{min}\end{array}$} & \multirow[b]{2}{*}{ Description of Tests } \\
\hline & & $\begin{array}{c}\text { During } \\
\text { consolidation }\end{array}$ & $\begin{array}{c}\text { During } \\
\text { shear }\end{array}$ & & \\
\hline \multirow{18}{*}{$\begin{array}{l}\text { Large } \\
\text { shear } \\
\text { box }\end{array}$} & L1 & 100 & 100 & 7.06 & \multirow{12}{*}{$\begin{array}{l}\text { Studies 1-3 } \\
\text { Carried out according to the test method Q1810 } \\
\text { using the large direct shear box on samples } \\
\text { with a particle size up to } 19 \mathrm{~mm} \text {, at a variety of } \\
\text { shearing rates }\end{array}$} \\
\hline & L2 & 100 & 100 & 0.63 & \\
\hline & L3 & 100 & 100 & 0.05 & \\
\hline & L4 & 200 & 200 & 7.06 & \\
\hline & L5 & 200 & 200 & 0.63 & \\
\hline & L6 & 200 & 200 & 0.05 & \\
\hline & L7 & 300 & 300 & 7.06 & \\
\hline & L8 & 300 & 300 & 0.63 & \\
\hline & L9 & 300 & 300 & 0.05 & \\
\hline & L10 & 400 & 400 & 7.06 & \\
\hline & L11 & 400 & 400 & 0.63 & \\
\hline & L12 & 400 & 400 & 0.05 & \\
\hline & L5 fine & 200 & 200 & 0.63 & \multirow{6}{*}{$\begin{array}{c}\text { Study } 2 \\
\text { Carried out on samples with the } 4.75 \mathrm{~mm} \text { to } \\
19 \mathrm{~mm} \text { fraction of particles removed } \\
\text { Study } \mathbf{3} \\
\text { In this case, the samples used had already been } \\
\text { subjected to a previous large shear box test }\end{array}$} \\
\hline & L8 fine & 300 & 300 & 0.63 & \\
\hline & L11 fine & 400 & 400 & 0.63 & \\
\hline & L1-2nd & 200 & 200 & 7.06 & \\
\hline & L4-2nd & 300 & 300 & 7.06 & \\
\hline & L7-2nd & 400 & 400 & 7.06 & \\
\hline \multirow{9}{*}{$\begin{array}{l}\text { Small } \\
\text { Shear } \\
\text { box }\end{array}$} & S1 & 124 & 124 & 6.70 & \multirow{9}{*}{$\begin{array}{c}\text { Studies } \mathbf{1} \text { and } \mathbf{2} \\
\text { Carried out according to the test method AS } \\
\text { 1289.6.2.2 using the small direct shear box on } \\
\text { samples with a particle size up to } 4.75 \mathrm{~mm} \text { at a } \\
\text { variety of shearing rates. }\end{array}$} \\
\hline & S2 & 124 & 124 & 0.44 & \\
\hline & S3 & 195 & 195 & 6.70 & \\
\hline & S4 & 195 & 195 & 0.44 & \\
\hline & S5 & 265 & 265 & 6.70 & \\
\hline & S6 & 265 & 265 & 0.44 & \\
\hline & S7 & 308 & 308 & 0.44 & \\
\hline & S8 & 406 & 406 & 6.70 & \\
\hline & S9 & 406 & 406 & 0.44 & \\
\hline
\end{tabular}

approach is unclear, and efforts to find an explanation in the literature have to date been unsuccessful. The basic steps in the procedure are:

- Monitor the change of height of the sample during the consolidation phase as a function of time;

- From a square-root time plot of the change in sample height, determine the value of the time to $100 \%$ consolidation $t_{100}$ by the construction shown in Fig. 2.

- Estimate the time to sample failure $t_{\mathrm{f}}$ by multiplying $t_{100}$ by a factor of 12.7 (Note that Q181C (2002) and ASTM D3080-98 (1998) adopt similar methods involving constants

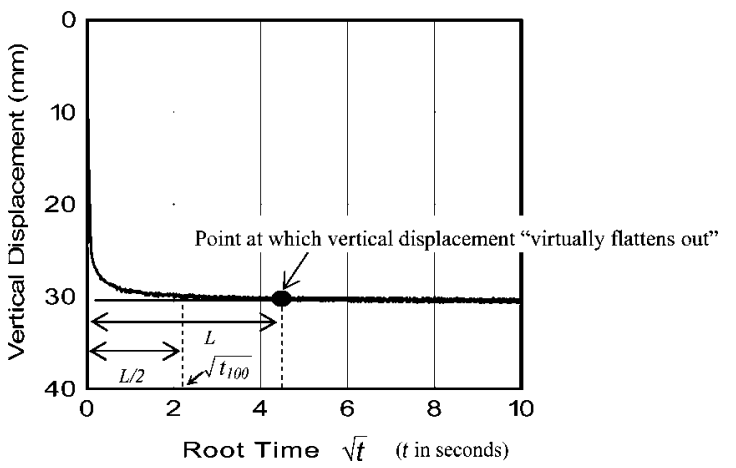

FIG. 2-Typical consolidation plot showing construction to determine $t_{100}$. to relate $t_{\mathrm{f}}$ to $t_{100}$ and $t_{90}$ (respectively), but neither provides an explanation to justify the constants used).

- Determine the appropriate shearing rate by dividing the time to failure by the distance $d_{\mathrm{cv}}$ that the sample should be sheared before constant volume conditions (i.e., zero change in sample height) are attained. There is a small problem with this approach, in that $d_{\mathrm{cv}}$ is not actually known until the test is completed, so it must be estimated prior to the test, at least for the first shearing stage of a new sample. As a guide, Q181C (2002) suggests that $d_{\mathrm{cv}}$ : should be between $5 \mathrm{~mm}$ and $8 \mathrm{~mm}$ for a $60 \mathrm{~mm}$ shear box and between $25 \mathrm{~mm}$ and $40 \mathrm{~mm}$ for a $300 \mathrm{~mm}$ shear box.

An example of this approach, applied to a test on the material used in this study, is presented in Fig. 2. Although the sample contains significant fine fractions, Fig. 2 shows that the primary consolidation of the sample under the applied normal load was relatively rapid.

Before going on to assess the absolute appropriateness of estimated shearing rate values, it is interesting to consider how consistent are the shearing rates predicted using actual consolidation data, with shearing rates estimated using the typical $d_{\mathrm{cv}}$ values in the method of Q181C. Consolidation settlements and consolidation times for many of the samples tested are given in Table 3. Measured consolidation times are used to estimate shearing rates, using the 
TABLE 3-The rates of consolidation and calculated shearing rates.

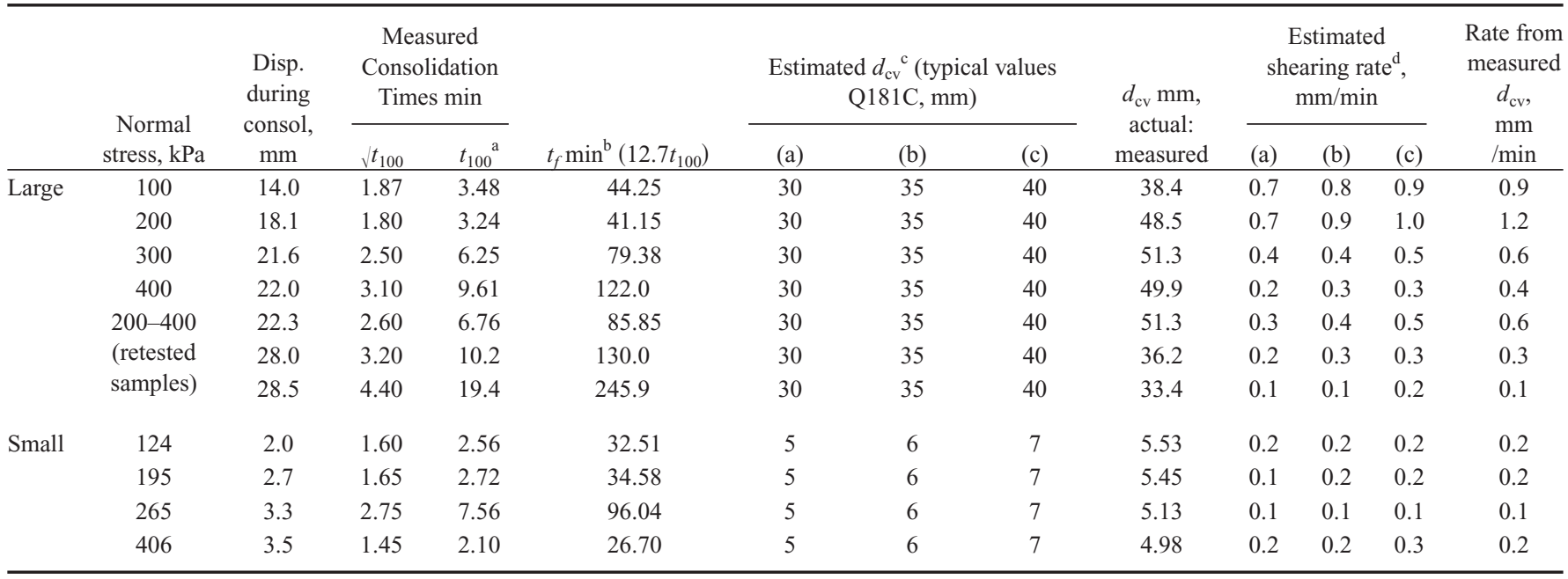

${ }^{\mathrm{a}} t_{100}=$ time for $100 \%$ primary consolidation to occur ( $\min$ ) (determined from consolidation curves; see Fig. 2).

${ }^{\mathrm{b}} t_{f}=$ time to failure under effective stress conditions ( $\mathrm{min}$ ) (calculated as $12.7 t_{100}$ ).

${ }^{\mathrm{c}} d_{\mathrm{cv}}=$ the horizontal displacement required to reach constant volume.

${ }^{\mathrm{d}} d_{\mathrm{cv}} / t_{f}=$ shearing rate.

measured $d_{\mathrm{cv}}$ values. Also, Table 3 presents a sensitivity analysis of estimated shearing rates using assumed $d_{\mathrm{cv}}$ values within the Q181C recommended range.

Using the method of Q181C (2002), all of the shearing speeds, based on assumed and measured values, fall between $1.2 \mathrm{~mm} / \mathrm{min}$ and $0.1 \mathrm{~mm} / \mathrm{min}$. The results confirm that the typical values offered by Q181C (2002) are appropriate, at least for material used in this study, as estimates of the shearing rates that would be predicted using its method. Looking more closely at the data in Table 3, it can be seen that the estimated shearing rates are relatively insensitive to the value of $d_{\mathrm{cv}}$ used in their calculation, with little difference between the estimated shearing rates predicted for $d_{\mathrm{cv}}$ values of $30 \mathrm{~mm}$ and $40 \mathrm{~mm}$.
In order to assess whether these shearing rate vales are actually appropriate to achieve drained testing conditions, we must consider the results of the direct shear tests. Basic details of these tests are presented in Table 4. Table 4 indicates that in all cases, the samples undergo significant densification after consolidation under the applied normal stress. For small and large boxes, the dry density of the loosely placed samples is about $1.4 \mathrm{t} / \mathrm{m}^{3}$, but after consolidation, there is a tendency for the large box samples to attain slightly higher dry density values. Also, when compared with the value of $1.86 \mathrm{t} / \mathrm{m}^{3}$ given in Table 1 for the maximum dry density achievable under standard compaction, it is apparent that in all cases, consolidation has failed to achieve this value. The results in Table 4 suggest

TABLE 4-Details of tested samples.

\begin{tabular}{|c|c|c|c|c|c|c|c|c|}
\hline \multirow[b]{2}{*}{$\begin{array}{l}\text { Specimen } \\
\text { number }\end{array}$} & \multirow[b]{2}{*}{$\begin{array}{c}\text { Normal } \\
\text { stress, } \\
\mathrm{kPa}\end{array}$} & \multirow[b]{2}{*}{$\begin{array}{c}\text { Shearing } \\
\text { rate, } \\
\mathrm{mm} / \mathrm{min}\end{array}$} & \multicolumn{2}{|c|}{ Pre-consolidation } & \multicolumn{4}{|c|}{ After consolidation/prior to shearing } \\
\hline & & & $\begin{array}{c}\text { Initial dry } \\
\text { density, } \\
\mathrm{t} / \mathrm{m}^{3}\end{array}$ & $\begin{array}{c}\text { Initial void } \\
\text { ratio } \\
e_{0}\end{array}$ & $\begin{array}{c}\text { Bulk density } \\
\text { prior to shear, } \\
t / \mathrm{m}^{3}\end{array}$ & $\begin{array}{c}\text { Dry density } \\
\text { prior to shear, } \\
t / \mathrm{m}^{3}\end{array}$ & $\begin{array}{c}\text { Void } \\
\text { ratio } \\
e_{\mathrm{f}} \\
\end{array}$ & $\begin{array}{c}\text { Water } \\
\text { content, } \\
\% \\
\end{array}$ \\
\hline \multicolumn{9}{|c|}{ Small box tests } \\
\hline $\mathrm{S} 1$ & 124 & 6.70 & 1.40 & 0.89 & 1.92 & 1.58 & 0.68 & 21.1 \\
\hline $\mathrm{S} 2$ & 124 & 0.44 & 1.40 & 0.89 & 1.94 & 1.62 & 0.64 & 19.9 \\
\hline $\mathrm{S} 3$ & 195 & 6.70 & 1.40 & 0.89 & 1.94 & 1.62 & 0.63 & 19.3 \\
\hline S4 & 195 & 0.44 & 1.40 & 0.89 & 1.94 & 1.62 & 0.63 & 19.3 \\
\hline S5 & 265 & 6.70 & 1.40 & 0.89 & 1.97 & 1.66 & 0.60 & 18.6 \\
\hline S6 & 265 & 0.44 & 1.40 & 0.89 & 1.99 & 1.68 & 0.58 & 18.1 \\
\hline S7 & 406 & 6.70 & 1.40 & 0.89 & 2.02 & 1.69 & 0.57 & 19.1 \\
\hline S8 & 406 & 0.44 & 1.40 & 0.89 & 2.02 & 1.70 & 0.55 & 18.4 \\
\hline \multicolumn{9}{|c|}{ Large box tests } \\
\hline $\mathrm{L} 1$ & 100 & 7.06 & 1.40 & 0.90 & 1.90 & 1.62 & 0.64 & 17.3 \\
\hline $\mathrm{L} 2$ & 100 & 0.63 & 1.40 & 0.89 & 1.95 & 1.63 & 0.62 & 19.4 \\
\hline L3 & 200 & 7.06 & 1.37 & 0.93 & 2.06 & 1.70 & 0.56 & 21.1 \\
\hline L4 & 200 & 0.63 & 1.38 & 0.92 & 1.95 & 1.65 & 0.61 & 18.1 \\
\hline L5 & 300 & 7.06 & 1.42 & 0.87 & 2.07 & 1.73 & 0.53 & 20.0 \\
\hline L6 & 300 & 0.63 & 1.41 & 0.88 & 2.01 & 1.74 & 0.52 & 15.7 \\
\hline L7 & 400 & 7.06 & 1.41 & 0.88 & 2.08 & 1.74 & 0.53 & 20.0 \\
\hline L8 & 400 & 0.63 & 1.40 & 0.89 & 1.91 & 1.65 & 0.61 & 15.7 \\
\hline
\end{tabular}



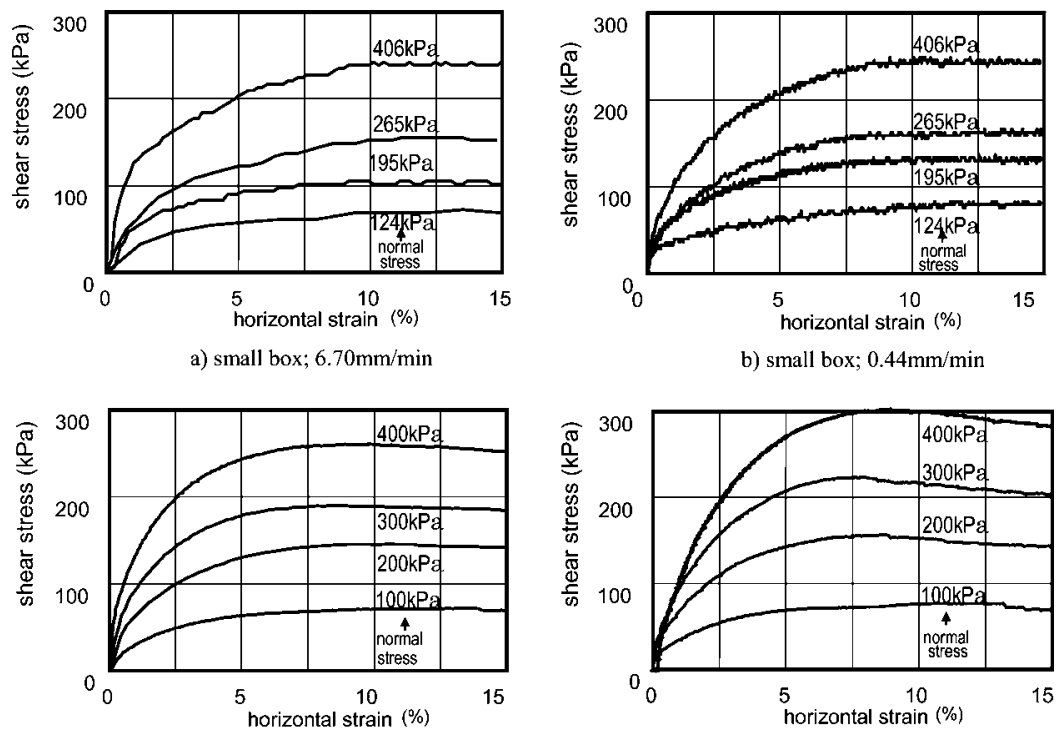

c) large box; $7.06 \mathrm{~mm} / \mathrm{min}$

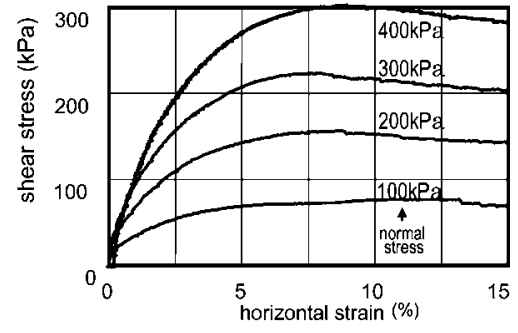

d) large box; $0.63 \mathrm{~mm} / \mathrm{min}$

FIG. 3-Shear stress-horizontal strain results for the tests reported in this study.

that the relative density of the prepared samples ranges from about $86 \%$ under a consolidation stress of $100 \mathrm{kPa}$, to $94 \%$ under a consolidation stress of $400 \mathrm{kPa}$.

Figures 3(a)-3(d) show the shear stress-horizontal strain curves for each of the tested samples. At both fast and slow shearing speeds, the results for the small box tests show a peak shear stress value being reached by around $10 \%$ strain. For shearing from $10 \%$ strain to $15 \%$ strain, the shear stress remains more or less constant, with only a slight suggestion in two of the results in Fig. 3(a) that this stress value might begin to decrease after the peak has been reached.

In contrast, the results for the large shear box show a tendency to attain a peak strength at strains of $7 \%$ to $10 \%$, and then a decrease in the measured shear strength to approach a lower residual strength. This behavior was most evident in the tests with the slower shear speed. The peak strength characteristic of the large box tests suggests that the slightly higher dry densities of these samples had some significant effect and is discussed further in the context of the following results.
The peak and residual shear strength values for each test have been interpreted from the results shown in Fig. 3. They are summarized in Table 5 and plotted as a function of normal stress in Figs. 4(a)-4(d). In almost all cases, for equivalent speeds, the large box results indicate higher shear strength values than the small box, even when the differences in the normal stress are taken into account. From the plotted results (Fig. 4), it is evident that reliable linear tends, passing through the origin, can be fitted to each data set, despite some small scatter in the results. The differences in the shear strength can be quantified by determining the slopes of the trendlines, and hence, estimating the effective friction angles (peak and residual/constant volume). These are given in Table 6 .

The effective friction angle results in Table 6 suggest that for the tested material in the large box, faster shearing speeds caused the effective friction angle to be underestimated by over $3.5^{\circ}$ and the residual effective friction angle to be underestimated by around $2^{\circ}$. They also suggest, however, that if the rate of shearing is very low, some underestimation (less than $1^{\circ}$ ) may also occur. For the tested material in the small box, the results are less consistent, with higher

TABLE 5-Summary of peak and residual shear strength values.

\begin{tabular}{|c|c|c|c|c|c|c|c|c|c|}
\hline \multicolumn{5}{|c|}{ Small shear box test results } & \multicolumn{5}{|c|}{ Large shear box test results } \\
\hline $\begin{array}{c}\text { Specimen } \\
\text { number }\end{array}$ & $\begin{array}{c}\text { Normal } \\
\text { stress, } \\
\mathrm{kPa} \\
\end{array}$ & $\begin{array}{l}\text { Shearing } \\
\text { rate, } \\
\mathrm{mm} / \mathrm{min}\end{array}$ & $\begin{array}{c}\text { Peak shear } \\
\text { strength, } \\
\mathrm{kPa} \\
\end{array}$ & $\begin{array}{c}\text { Residual } \\
\text { shear } \\
\text { strength, } \\
\mathrm{kPa} \\
\end{array}$ & $\begin{array}{c}\text { Specimen } \\
\text { number }\end{array}$ & $\begin{array}{c}\text { Normal } \\
\text { stress, } \\
\mathrm{kPa}\end{array}$ & $\begin{array}{c}\text { Shearing } \\
\text { rate, } \\
\mathrm{mm} / \mathrm{min}\end{array}$ & $\begin{array}{c}\text { Peak shear } \\
\text { strength, } \\
\mathrm{kPa}\end{array}$ & $\begin{array}{c}\text { Residual } \\
\text { shear } \\
\text { strength, } \\
\mathrm{kPa} \\
\end{array}$ \\
\hline $\mathrm{S} 1$ & 124 & 6.70 & 68.6 & 68.6 & L1 & 100 & 7.06 & 72.1 & 69.2 \\
\hline $\mathrm{S} 2$ & 124 & 0.44 & 79.5 & 79.5 & L2 & 100 & 0.63 & 77.2 & 70.6 \\
\hline S3 & 195 & 6.70 & 104.7 & 104.7 & L3 & 100 & 0.05 & 77.0 & 74.8 \\
\hline S4 & 195 & 0.44 & 130.0 & 130.0 & L4 & 200 & 7.06 & 146.1 & 140.4 \\
\hline S5 & 265 & 6.70 & 155.3 & 155.3 & L5 & 200 & 0.63 & 156.8 & 140.4 \\
\hline S6 & 265 & 0.44 & 162.5 & 162.5 & L6 & 200 & 0.05 & 153.1 & 142.2 \\
\hline S7 & 406 & 6.70 & 238.4 & 238.4 & L7 & 300 & 7.06 & 190.3 & 183.3 \\
\hline \multirow[t]{5}{*}{ S8 } & 406 & 0.44 & 242.0 & 242.0 & L8 & 300 & 0.63 & 223.7 & 197.0 \\
\hline & & & & & L9 & 300 & 0.05 & 223.1 & 204.0 \\
\hline & & & & & L10 & 400 & 7.06 & 261.2 & 250.8 \\
\hline & & & & & L11 & 400 & 0.63 & 302.9 & 275.5 \\
\hline & & & & & L12 & 400 & 0.05 & 286.6 & 269.2 \\
\hline
\end{tabular}



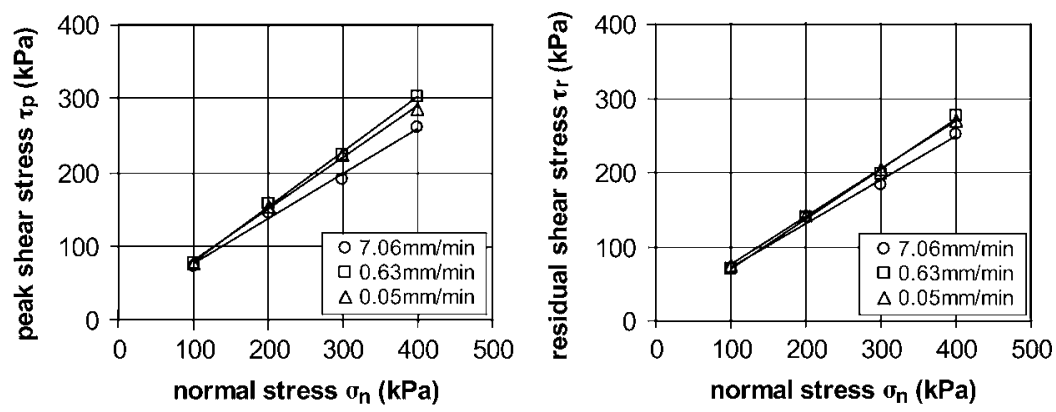

results for large $(300 \times 300 \mathrm{~mm})$ box.
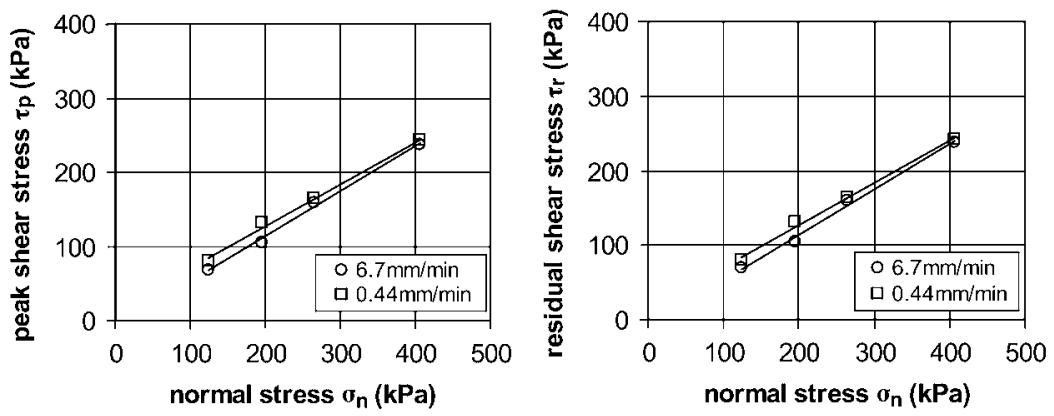

results for small $(60 \times 60 \mathrm{~mm})$ box.

FIG. 4-Comparison of results for different shearing rates in large and small boxes.

peak strengths at the faster speed, but higher residual strength at the lower speed. These results are discussed in the next section.

\section{Results of Study 2: The Effect of the Scale of the Test}

As was noted in the previous section in almost all cases, the large box results indicate higher shear strength values than the small box. To explore the reasons for this, we consider first the effect of box size only, by comparing results for tests with large and small boxes, sheared at similar speeds, each using sample prepared with a maximum particle size of $4.75 \mathrm{~mm}$. The shearing results for these tests are shown in Fig. 5(a), while the peak and residual shear strength values are shown in Fig. 5(b).

Figure 5(a) shows that the large box test results exhibit some amount of peak strength behavior, whereas the small box tests do not. Despite small differences in the applied normal stress, the results are very similar. Figure $5(b)$ shows the plots of shear stressnormal stress from which the peak and residual effective friction angles were determined. The peak/residual effective friction angle for the small box test was $31.6^{\circ}$, as was the residual strength value for the large box test. The peak strength for the large box test was slightly higher at $32.8^{\circ}$. As is evident from Fig. $5(b)$, however, this difference is relatively small, and of dubious significance given the variability inherent in the results.

We now consider the effect of maximum particle size, by comparing results from large box tests at $0.63 \mathrm{~mm} / \mathrm{min}$, but using materials with different maximum particle size. The shearing results for these tests are shown in Fig. 6(a) while the peak and residual shear strength values are shown in Fig. $6(b)$.

Figure $6(a)$ shows that all of the large box test results display strong peak strength behavior, and that the tests on coarser samples record significantly higher shear strengths. Figure $6(b)$ shows the plots of shear stress-normal stress from which peak and residual effective friction angles were again determined. The peak and residual effective friction angles for the $<4.75 \mathrm{~mm}$ sample tests were $32.8^{\circ}$ and $31.6^{\circ}$, whereas the peak and residual strengths for the $<19 \mathrm{~mm}$ sample tests were much higher at $37.1^{\circ}$ and $34.2^{\circ}$. Compared with the differences caused by the different sized boxes, these are very significant. These results indicate that the higher effective shear strength values measured using large shear boxes result mostly from the presence of larger particles, with little of the effect being due to the size of the shear boxes used in the test. The significance of this is discussed in the discussion section.

TABLE 6-Comparison of effective friction angles determined using the small and large shear boxes.

\begin{tabular}{|c|c|c|c|c|}
\hline \multirow[b]{3}{*}{ Test type } & \multicolumn{4}{|c|}{ Effective internal friction angle $\varphi^{\prime},{ }^{\text {a }}$} \\
\hline & \multicolumn{2}{|c|}{ Peak } & \multicolumn{2}{|c|}{ Residual/constant volume } \\
\hline & Large shear box & Small shear box & Large shear box & Small shear box \\
\hline Fast shear & $33.4(7.06 \mathrm{~mm} / \mathrm{min})$ & $\mathbf{3 0 . 2}(6.70 \mathrm{~mm} / \mathrm{min})$ & $32.4(7.06 \mathrm{~mm} / \mathrm{min})$ & $\mathbf{3 0 . 2}(6.70 \mathrm{~mm} / \mathrm{min})$ \\
\hline Slow shear & $37.1(0.63 \mathrm{~mm} / \mathrm{min})$ & $31.6(0.44 \mathrm{~mm} / \mathrm{min})$ & $34.3(0.63 \mathrm{~mm} / \mathrm{min})$ & $31.6(0.44 \mathrm{~mm} / \mathrm{min})$ \\
\hline V.Slow shear & $36.2(0.05 \mathrm{~mm} / \mathrm{min})$ & & $\mathbf{3 4 . 3}(0.05 \mathrm{~mm} / \mathrm{min})$ & \\
\hline
\end{tabular}

${ }^{\mathrm{a}}$ Trendlines fitted to pass through the origin. 


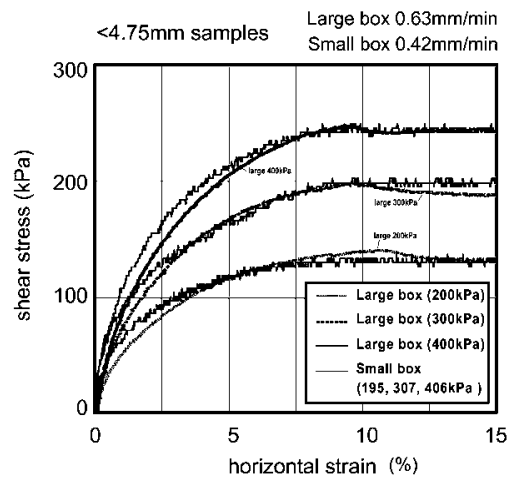

a) Shear stress - strain curves for small and large samples

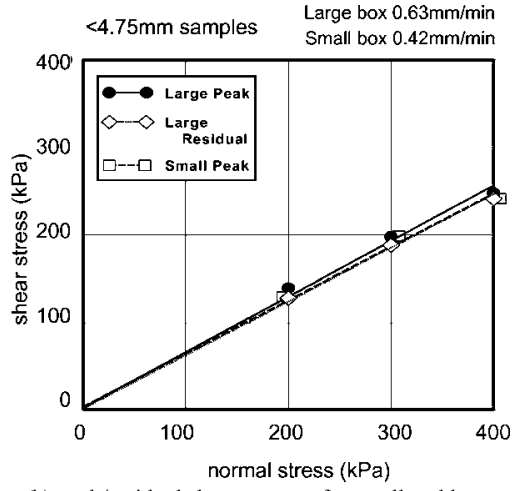

b) peak/residual shear stresses for small and large samples

FIG. 5-Comparison of results to assess the effect of different box sizes.

\section{Results of Study 3: The Effect of Retesting the Same Sample}

A comparison of results for tests on fresh and previously tested samples is presented in Fig. 7.

The results of Fig. 7 indicate a consistent and significant decrease in shear strength for samples that are tested a second time. Figure 7(a) shows that retested samples not only have lower shear strengths overall, but they exhibit little if any sign of peak strength behavior. Figure $7(b)$ summarizes the relationship between shear strength and normal stress, and it demonstrates a clear and signifi- cant reduction in the measured effective angle of friction. The predicted peak friction is reduced from $33.4^{\circ}$ to $28^{\circ}$ by the retesting of the sample, while the residual angle of friction if reduced from around $32.4^{\circ}$ also to $28^{\circ}$. These reductions are significant and are they discussed further in the next section.

\section{Discussion}

Despite the inconsistency in the trends from the small shear box, there seems to be sufficient support to conclude that a shearing rate

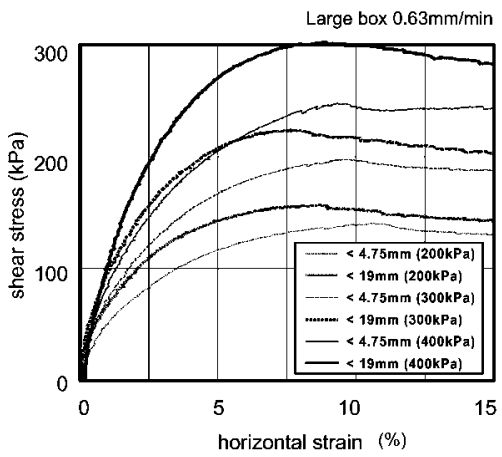

a) Shear stress - strain curves for fine and coarse samples

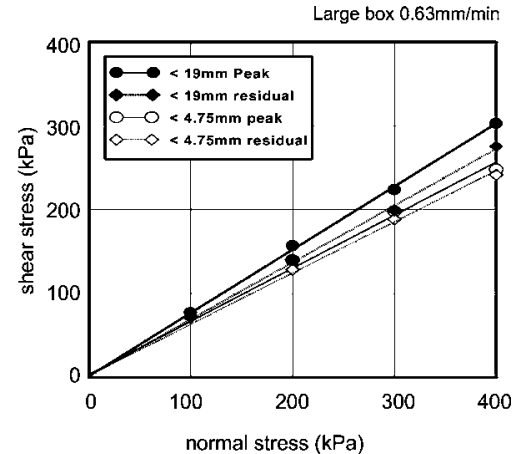

b) peak/residual shear stresses for fine and coarse samples

FIG. 6-Comparison of results to assess the effect of different box sizes.

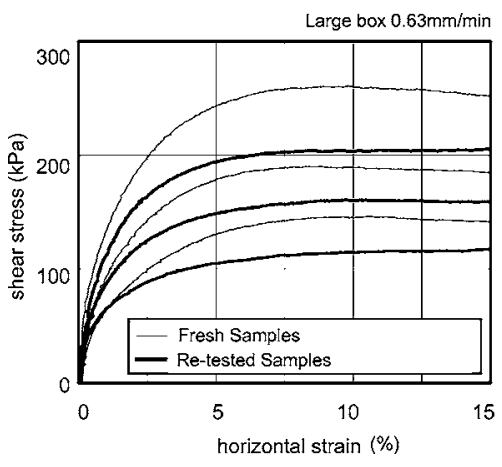

a) Shear stress - horizontal strain behavior.

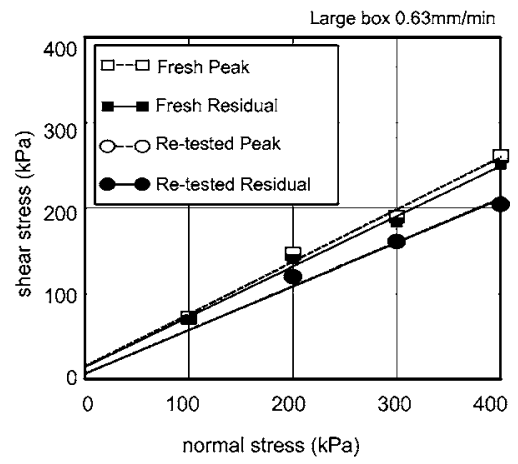

b) Shear stress - normal stress results.

FIG. 7-Results for tests on fresh and previously tested samples. 


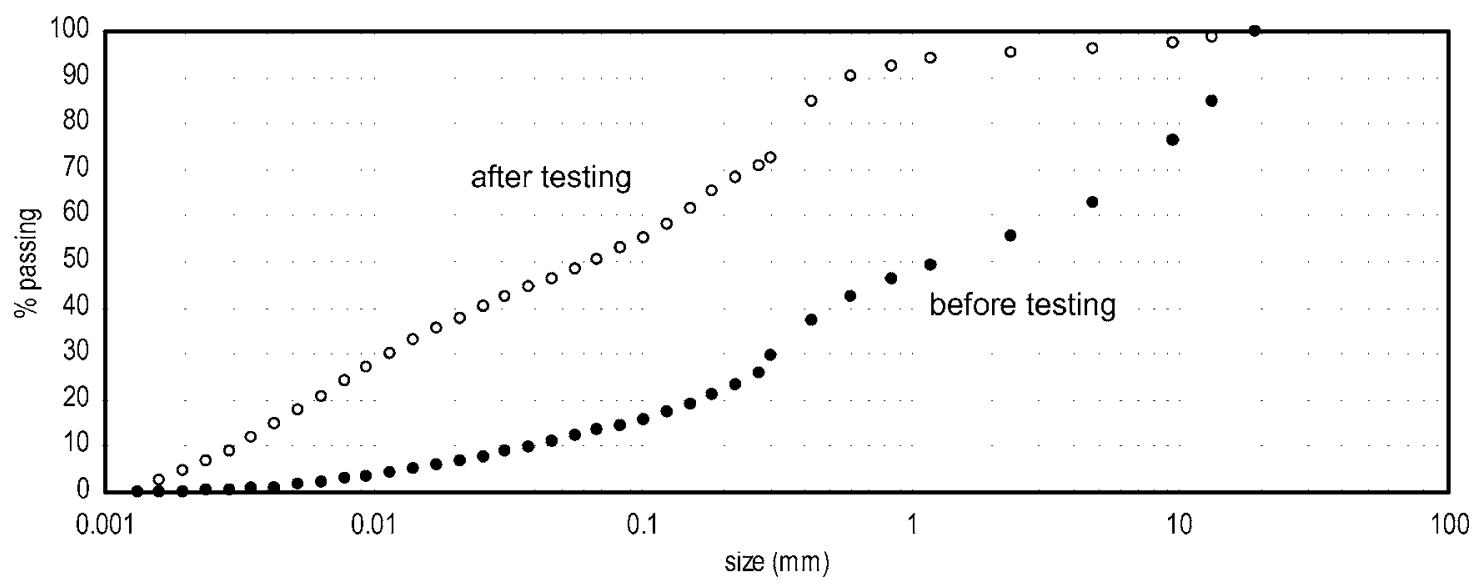

FIG. 8-Particle size distributions of a sample, before and after being subjected to direct shear testing.

of around $7 \mathrm{~mm} / \mathrm{min}$ is too fast to ensure fully drained (and hence maximum effective friction) behavior to be determined for the tested material using the large shear box. A shearing rate of around ten times slower would seem to give significantly higher effective friction angle values, but 100 times slower will give similar or even slightly reduced values. Although aspects of this response may seem at first unlikely, they are in fact consistent with behaviors reported in the literature. They confirm that the behavior of the marginal material tested here is generally consistent with that accepted that for granular backfills. They also confirm that a shearing rate of around of $1 \mathrm{~mm} / \mathrm{min}$ is probably appropriate (Jewell and Wroth 1987; Bauer and Zhao 1993). The apparent reduction in shear strength at lower shearing rates is also a reasonable outcome, when interpreted in the context of the observations of Yamamuro and Lade (1993), who found that soil specimens were less compressive and their apparent strengths were increased, when the rate of strain was increased. Drained shearing at lower strain rates allows more time for particle crushing and rearrangement, and so, the soil appears more compressible and less dilatant, thus exhibiting slightly lower strength. There may be some justification to suggest that rates slower than those prescribed in Q181C may produce an effective friction angle that is more applicable to the low strain rate conditions that may occur in practice, but further consideration of this is beyond the scope of the present discussion.

The results here suggest that the underestimation in the effective friction angle from shearing at too high a rate is likely to be significant when assessing the compliance of marginal materials (similar to those used here) to some prescribed value. They also suggest that the shearing rates estimated using Q181C $-0.1-1.2 \mathrm{~mm} / \mathrm{min}$ for this material (see Table 3) - are likely to be appropriate to produce a truly drained response, without being unnecessarily slow and making the tests unacceptably long.

The results assessing the effects due to the scale of the test seem to conclusively indicate that the significance of testing using a larger box is due to the presence of the larger particles $(9.6-19 \mathrm{~mm})$ in the sample tested, and not to the larger overall size of the sample. The effect is significant, particularly considering that the coarser gravel fraction $(4.75-19 \mathrm{~mm})$ made up only $9 \%$ of the large box samples. It is considered that particle breakage should increase in soils containing coarser particles, since the potential for mechanical interference to shearing is greater. This should in turn lead to an increase in the shear strength of coarser soils. These ideas are consistent with the results obtained here. Lee and Seed (1967) found that, under high pressure, the shear strength of a coarser soil is greater, even though the dilatancy may be lower. This is consistent with the findings of this study. Lee and Seed (1967) suggested that the strength increase in such cases was due to particle crushing during shearing at high pressure. The same behavior is likely to prevail here, not because the confining pressure is high, but because for a siltstone, the particle strength is low. In tests on compacted mudstones, Nobuyuki et al. (2002) found that the strength of the aggregates has a significant influence on the strength of the compacted sample.

The results obtained here demonstrate that small shear box tests are no substitute for large shear box tests, and that downsizing the grading and the size of the sample tested will cause the effective friction angle to be under-estimated by as much as $4^{\circ}$. This would not be to the advantage of a contractor trying to use marginal materials. If a sample contains coarser particles, it can be tested using a direct shear testing machine of any size, provided the constraints on maximum particle size are respected. For the soils commonly used in the construction industry, with particle sizes up to $70-100 \mathrm{~mm}$, this means that coarser size fractions must be removed prior to testing. This suggests that even if a $300 \mathrm{~mm}$ shear box is used to perform tests on a sample with particles up to $19 \mathrm{~mm}$, the result is likely to be a slight under-estimate of the true strength of a coarser material. This is conservative.

The results to demonstrate the effect of retesting samples are consistent with expectation, given the nature of the marginal material used in this study. They indicate a reduction in the measured angle of friction of $4-5^{\circ}$. This could also have a significant effect of the assessment of marginal materials, relative to some specified minimum value of the effective friction angle. There is, thus, no advantage in trying to retest a previously tested sample.

The role played by the larger particles in increasing the effective angle of friction was discussed above. It the context of the results for retested samples, it is interesting to compare the changes that occur to the grading curve during a single direct shear test. Figure 8 shows two grading curves corresponding to the before and after particle characteristics of a sample submitted to a direct shear test.

From Fig. 8, it is clear that the processes of saturation, consolidation, shearing, and sample recovery cause a significant reduction in the sizes of particles within the sample. Figure 8 indicates that almost all particles greater than $10 \mathrm{~mm}$ are eliminated, and that the proportion of particles greater than $1 \mathrm{~mm}$ is reduced from around $50 \%$ to around $8 \%$. The measured reduction in shear strength is thus, not surprising. 


\section{Conclusions}

Despite being well established as a primary tool for shear strength assessment in geomechanics, there is relatively little published literature on the direct shear test, at least in the last 40 years or so. While many of the important aspects of this test are specified in testing standards, or known informally or intuitively by practitioners, the basis for much of what is commonly understood or specified is hard to locate in the technical literature.

This paper presents a study of direct shear testing applied to a granular material of marginal quality. By using the testing standard Q181C as an example, it demonstrates that the available test method specifications produce results that are consistent with theoretical considerations, and are able to produce results that are reasonable, conservative estimates of the quantity they are intended to measure. It also demonstrates that shortcuts in the testing of coarse granular materials will lead to significant differences in the measured results, that in most cases, are more conservative than results obtained by adhering to the correct procedure. These shortcuts include testing a sample of reduced size in a small box, shearing the sample too quickly, and testing the same sample more than once. The significance of the under-estimation in each case is likely to be significant in regard to marginal materials, which may already have difficulty meeting material quality specifications.

\section{Acknowledgments}

The authors would like to thank Yamaguchi University and the University of Newcastle for facilitating the collaboration agreement that made this research possible. The authors would also like to thank Professor Masayuki Hyodo for making this joint research possible.

\section{References}

Abderrahim, A., and Tisot, J. P., 1993, "Friction at the Cohesionless Soil-Structure Interface: Effect of Various Parameters According to a Classic Study and a New Approach," Geotech. Test. J., Vol. 16, pp. 122-130.

AS 1141.23, 1999, "Los Angeles Number" Methods of Sampling and Testing Aggregates, Standards Association of Australia, Sydney.

AS 1289.5.1.1, 2003, "Soil Compaction and Density Tests Determination of the Dry Density/Moisture Content Relation of a Soil Using Standard Compactive Effort," Methods of Testing Soils for Engineering Purposes, Standards Association of Australia, Sydney.

AS 1289.6.2.2, 1998, "Soil Strength and Consolidation Tests Determination of the Shear Strength of a Soil: Direct Shear Test Using a Shear Box," Methods of testing soils for engineering purposes, Standards Association of Australia, Sydney.

ASTM D3080-98, 1998, Standard Test Method for Direct Shear Test of Soils Under Consolidated Drained Conditions, ASTM International, West Conshochocken, PA.

Bauer, G. E., and Zhao, Y., 1993, "Shear Strength Tests for Coarse Granular Backfill and Reinforced Soils," Geotech. Test. J., Vol. 16, pp. 115-121.
Day, R. A., 1995, "Discussion on Numerical Analysis of Drained Direct and Simple Shear Tests," J. Geotech. Engrg., Vol. 121, pp. 223-227.

Dounias, G., and Potts, D., 1993, "Numerical Analysis of Drained Direct and Simple Shear Tests," J. Geotech. Engrg., Vol. 119, pp. 1870-1891.

Finno, R., Harris, W., Mooney, M., and Viggiani, G., 1997 "Shear Bands in Plane Strain Compression of Loose Sands," Geotechnique, Vol. 47, pp. 149-165.

Han, C., and Drescher, A., 1993, "Shear Bands in Biaxial Tests on Dry Coarse Sands," Soils Found., Vol. 33, pp. 118-132.

Hausmann, M., 1990, Engineering Principles of Ground Modification, McGraw-Hill, New York.

Jewell, R. A., and Wroth, C. P., 1987, "Direct Shear Tests on Reinforced Sand," Geotectonics, Vol. 37, pp. 53-68.

Kovacs, W. D., 1997, "The Karol-Warner Direct Shear Testing Machine," Internal Report, University of Washington, Seattle WA.

Lamb, T. W., and Whitman, R. V., 1969, Soil Mechanics, John Wiley and Sons, New York.

Lay, M. G., 1985, Source Book for Australian Roads, 3rd Ed. Australian Road Research Board, Melbourne.

Lee, K. M., and Manjunath, V. R., 2000, "Soil-Geotextile Interface Friction by Direct Shear Tests," Can. Geotech. J., Vol. 37, pp. 238-252.

Lee, K. L., and Seed, H. B., 1967, "Drained Strength Characteristics of Sand," J. Soil Mech. and Found. Div., Vol. 93, No. SM6, pp. 117-141.

Muhlhaus, H. B., and Vardoulakis, I., 1987, "The Thickness of Shear Bands in Granular Materials," Geotechnique, Vol. 37, pp. 271-285.

Nobuyuki, Y., Enami, K., and Koichi, H., 2002, "Staged Compression-Immersion Direct Shear Test on Compacted Crushed Shale," J. Test. Eval., Vol. 40, pp. 239-244.

Palmeira, E. M., and Milligan, G. W., 1989, "Scale Effects in Direct Shear Tests on Sand," Proceedings of 12th International Conference on Soil Mechanics and Foundation Engineering, pp. 739742.

Palmer, A. C., 1999, "Speed Effects in Cutting and Ploughing," Geotechnique, Vol. 49, pp. 285-294.

Q181C, 1994, Effective Angle of Internal Friction at Constant Volume Conditions for Granular Materials - Draft, Queensland Main Roads, Brisbane Q1d, Australia.

Q181C, 2002, Effective Angle of Internal Friction at Constant Volume Conditions for Granular Materials Queensland Main Roads, Brisbane Old, Australia.

Roscoe, K. H., 1970, "The Influence of Strains in Soil Mechanics," Geotechnique, Vol. 20, pp. 129-170.

Saada, A. S., and Townsend, F. C., 1981, "State of the Art: Laboratory Strength Testing of Soils," D. Yong and F. C. Townsend, Eds., Laboratory Shear Strength of Soil, ASTM STP 740, ASTM International, West Conshohocken, PA. pp. 7-77.

Takada, N., 1993, "Mikasa's Direct Shear Apparatus, Test Procedures and Results," Geotech. Test. J., Vol. 16, pp. 314-322.

Terzaghi, K., Peck, R., and Mesri, G., 1996, Soil Mechanics in Engineering Practice, John Wiley and Sons, New York.

Yamamuro, J. A., and Lade, P. V., 1993, "Effects of Strain Rate on Instability of Granular Soils," Geotech. Test. J., Vol. 16, pp. 304-313. 